\title{
Measuring the Market Efficiency of Housing Market in China: Based on the Perspective of Disequilibrium
}

\author{
Botao Lu, Chengzhang Wang \\ School of Economics and Management, Southwest Jiaotong University, Chengdu, China \\ Email: tmlbt1978@163.com
}

Received 12 May 2015; accepted 9 June 2015; published 12 June 2015

Copyright (C) 2015 by authors and Scientific Research Publishing Inc.

This work is licensed under the Creative Commons Attribution International License (CC BY). http://creativecommons.org/licenses/by/4.0/ (c) (i) Open Access

\begin{abstract}
Based on the disequilibrium theory, the paper measured the market efficiency of housing market in China from 1998 to 2013 by constructing the econometric model. The proposed methods and model can solve the problem of how to quantize the market efficiency in a disequilibrium market, which will sever the purpose for indicating the market status and improving the market operation. The results showed that: during 1998 and 2013, Chinese housing market had been in a state of disequilibrium, and housing market efficiency was high and on the rise, which showed that Chinese macroeconomic regulation against real estate played an important role.
\end{abstract}

\section{Keywords}

Housing Market, Disequilibrium, Market Efficiency

\section{Introduction}

In the past few years, housing vacancy rate in China was high. The entire housing vacancy rate in Chinese urban was $22.4 \%$ in 2013 reported by Chinese family financial investigation and research center in the Southwestern University of Finance and Economics. According to common international practice, the housing vacancy rate between $5 \%$ and $10 \%$ is reasonable, which reflects that housing supply and demand is balanced and it is conducive to the development of national economy. The vacancy rate between $10 \%$ and $20 \%$ is danger and if it is more than $20 \%$, the real estate will crash. According to the basic principles of economics, the high housing vacancy rate in China reflects that the housing supply greatly exceeds the demand and the house prices should fall. At the same time, however, the house prices in China are rising and many consumers want to buy a house but not get one. Housing market in China is in a situation where "shortage" and "lag" coexist, which perhaps shows 
the housing market in China is in disequilibrium and inefficient.

In fact, disequilibrium is also a kind of equilibrium which is different from the Walrasian equilibrium. In disequilibrium, there is no sensitive price system in the market and the effective supply is not equal to the effective demand [1]. Market efficiency was generally defined in the Walrasian equilibrium. But in reality the Walrasian equilibrium nearly does not always exist. Market efficiency in this paper is different from the traditional definition. According to the definition (Benassy, 1987) that market efficiency refers to all mutually beneficial transactions can be completed in the market operation. This is also known as there is no friction in the market [2]. By this definition, the total trading volume $Q$ and total supply $S$ meet the following "short edge rule", $Q=\min (D$, $S$ ). In reality, buyers and sellers are restricted by various factors and they can't make mutual beneficial trade. The actual transactions in the real estate market thus do not exceed short of supply and demand side, that is to say, the $Q \leq \min (D, S)$ [2]. If the actual trading volume is less than the short of supply and demand side, the market efficiency is low.

This paper attempts to measure the size of the market efficiency from the perspective of market disequilibrium, which will show how much the real estate market in China meets the "short edge rule".

\section{Model and Data}

\subsection{Model}

Based on the research of eastern European economies, Kornal (1986) thought that "Short edge rule" was not met in reality due to the existence of all kinds of trade friction and the market trading volume was always less than the minimum quantity between supply and demand, namely $Q<\min (D, S)$ [3]. Along the analysis of Kornal (1986), Burkett (1988) established the following hyperbolic model:

$$
|(D-Q) / D| \times|(S-Q) / S|=r^{2}
$$

where $D, S, Q$ represents effective market demand, effective market supply and actual trade volume respectively and $\mathrm{r}$ is the market friction index. As we know, for the reality of economic, $r>0$ is always true, namely $Q<\min$ $(D, S)$. When $r$ converges to zero, the actual volume $Q$ is the smaller one between $D$ and $S$ [4]. In this paper, the model is used to quantify the trade friction.

This paper argues that it is efficient as long as market equilibrium meets the "short edge rule" and if "shortage" and "lag" coexist, namely $Q<\min (D, S)$, the market is lack of efficiency. Since $\mathrm{r}$ is a measurement of market friction, we defined $E$ as the size of market efficiency, namely, $E=1-r, 0 \leq E \leq 1 . E=1$ indicates the market efficiency is highest, and $E=0$ indicates market is inefficiency. Obviously, if we are able to quantify the friction coefficient " $r$ ", market efficiency $E$ will get. We assume the effective market demand of house in China is $D$ and effective market supply is $S$, then by (1) we work out the equation of housing market trading volume $Q$ as follow:

$$
Q=\frac{1}{2}(D+S)-\frac{1}{2} \sqrt{(D-S)^{2}+4 r^{2} D S}
$$

The corresponding econometrics equation is:

$$
Q=\frac{1}{2}(D+S)-\frac{1}{2} \sqrt{(D-S)^{2}+4 r^{2} D S}+\varepsilon
$$

where $\varepsilon$ is the classic error term. If we know the specific mathematical equation of the demand and supply function, we can estimate the Equation (3).

There are many factors which can influence the housing supply and demand, such as housing prices, disposable income and wealth, family number, housing policy, the size of housing investment, loans rate, lands price and so on [5]-[8]. Some scholars at home and abroad have researched China's real estate market demand function and supply function [9]-[11]. On the basis of considering these research results, the paper built the following housing demand and supply functions:

The effective house demand function is:

$$
D=\beta_{1}+\beta_{2} p+\beta_{3} y+\beta_{4} i
$$

where $D$ denotes effective housing demand, $y$ denotes urban per capita disposable income, $p$ denotes the relative 
prices of housing sales price (national housing sales price divided by the consumer price index (CPI), $i$ denotes more than 5-year lending rates for financial institutions.

The effective housing supply function is:

$$
S=\beta_{5}+\beta_{6} p+\beta_{7} c+\beta_{8} i
$$

where $S$ is effective housing supply, $p$ and $i$ is the same meaning as above, $c$ means construction costs which are represented as the total investment made by real estate enterprises [8]. In this paper, commercial housing sales areas every year are representative in the actual housing trading volume. If we replace the expression of $S$ and $D$ in (4) and (5) into econometrics Equation (3), we can get the following equation:

$$
\begin{aligned}
& Q=0.5\left(\beta_{1}+\beta_{2} p+\beta_{3} y+\beta_{4} i+\beta_{5}+\beta_{6} p+\beta_{7} c+\beta_{8} i\right) \\
& -0.5 \sqrt{\left(\beta_{1}+\beta_{2} p+\beta_{3} y+\beta_{4} i-\beta_{5}-\beta_{6} p-\beta_{7} c-\beta_{8} i\right)^{2}+4 r^{2}\left(\beta_{1}+\beta_{2} p+\beta_{3} y+\beta_{4} i\right)\left(\beta_{5}+\beta_{6} p+\beta_{7} c+\beta_{8} i\right)}+\varepsilon
\end{aligned}
$$

\subsection{Data}

In China, the policy of stopping the welfare housing distribution for urban residents begin from 1998 and the monetization of housing distribution is gradually implement, which means marketization of Chinese real estate industry began to run. Therefore, we select the relevant data from 1998 to 2013. Data set $i$ are from the website of the people's bank of China which is the central bank in China and other data from China statistical yearbook. For $i$, because the central bank adjust it for several times within one year, this article process with the method of arithmetic average. And for $y, p$ as well as $c$ (real estate enterprises investment data), we processed them with the CPI index in 1978 as the base year. At the same time, in order to weaken or eliminate the heteroscedasticity, we take the natural logarithm for each variable (except lending rates), see Table 1.

\section{Estimation and Analysis}

\subsection{Estimation of the Parameters}

In this paper, we got the estimation of the parameters in the model with Stata 12.0 and the estimation process is divided into the following steps [12]:

Table 1. Time series data from1998 to 2013.

\begin{tabular}{cccccc}
\hline Year & $\begin{array}{c}\text { lnQ } \\
\text { (Thousands of square meters) }\end{array}$ & Iny (yuan) & $\begin{array}{c}\text { Lnc } \\
\text { (One hundred million yuan) }\end{array}$ & $\begin{array}{c}i \\
\text { (\%) }\end{array}$ & $\begin{array}{c}\text { Inp } \\
\text { (yuan) }\end{array}$ \\
\hline 1998 & 9.41 & 9.47 & 6.71 & 9.18 & 6.15 \\
1999 & 9.59 & 9.46 & 6.86 & 6.80 & 6.16 \\
2000 & 9.83 & 9.48 & 7.05 & 6.21 & 6.19 \\
2001 & 10.02 & 9.50 & 7.28 & 6.21 & 6.21 \\
2002 & 10.20 & 9.51 & 7.49 & 5.82 & 6.25 \\
2003 & 10.43 & 9.53 & 7.75 & 5.76 & 6.29 \\
2004 & 10.55 & 9.60 & 7.97 & 5.84 & 6.41 \\
2005 & 10.92 & 9.64 & 8.14 & 6.12 & 6.53 \\
2006 & 11.03 & 9.67 & 8.32 & 6.47 & 6.57 \\
2007 & 11.26 & 9.75 & 8.54 & 7.34 & 6.66 \\
2008 & 11.10 & 9.82 & 8.69 & 7.46 & 6.59 \\
2009 & 11.46 & 9.82 & 8.85 & 5.94 & 6.80 \\
2010 & 11.56 & 9.89 & 9.11 & 5.98 & 6.84 \\
2011 & 11.60 & 9.97 & 9.30 & 6.85 & 6.85 \\
2012 & 11.62 & 9.99 & 9.42 & 6.80 & 6.59 \\
2013 & 11.78 & 10.01 & 9.58 & 6.95 & 6.96 \\
\hline
\end{tabular}

Source: China statistical yearbook. 
1. Under the assumption that housing markets in China are clear, we estimate the coefficients in demand equation (4) and supply equations (5) with ordinary least square, respectively.

2. After a preliminary estimation, we check whether the estimated coefficients met a variety of statistical tests, if yes, go into the next step 3, otherwise, we would check the data or reset variables in the equations.

3. Estimating the equation (6) with the nonlinear least squares with taking coefficient values in step 2 as the initial values.

In order to eliminate the influence of the serial correlation of the time series data, we make estimation for equations (4) and (5) with New-West standard error. Eventually, the first step estimation results are as follows:

Table 2 shows that each coefficient meets the statistical tests. Therefore, we can go to step 3 directly. On the choice of the initial value of the friction coefficient $r$, in this paper, after many attempts, 0.00075 is finally chosen as the initial value. The final estimated results are as follows:

$$
\begin{aligned}
\ln D_{t} & =-0.94+2.64 \ln p_{t}-0.72 \ln y_{t}+0.07 i_{t} \\
\ln S_{t} & =-0.74+0.49 \ln p_{t}-0.02 \ln c_{t}+1.09 i_{t} \\
& \ln Q_{t} \leq \min \left(\ln D_{t}, \ln S_{t}\right)
\end{aligned}
$$

If we take the relevant data into (1), the market efficiency " $E$ " every year can be calculated with (7).

\subsection{Analysis of the Estimation Results}

The following Table 3 lists the all relevant estimates:

Table 3 shows that there was a gap between the actual housing trade volume and effective demand volume and effective supply volume in Chinese housing market during 1998 and 2013, which indicates that Chinese housing market had been in a state of disequilibrium. We define the degree of disequilibrium $Z=(\ln D-\ln S) /$ $\ln Q$, which is used to measure the strength and direction of disequilibrium in the housing market. The greater is the absolute value of $Z$, the stronger is the unbalanced degree of the market. If $Z$ is positive, the market demand is greater than supply, namely supply in the short side. If $Z$ is negative, the market supply is greater than the demand, namely demand in the short side [13]. In order to analysis the change of the efficiency of housing market in China, we draw the time sequence diagram of the unbalanced degree of $Z$ and market efficiency $E$, see Diagram 1 and Diagram 2.

As can be seen from the Figure 1:

(1) $Z$ was negative during 1998-2013, which showed the housing market in China was at the short side of demand and reflected that the deficiency of effective demand was deficient and effective supply of housing market in China was excess. The cause of deficiency of effective demand is mainly that per capita income growth rate of urban residents in China can't keep up with the growth rate of house prices. Excess effective supply was mainly caused by two reasons, one is the tax reform since 1994 in China and the other is the narrow investment

\begin{tabular}{|c|c|c|}
\hline Indicators & $\ln D=\ln Q$ & $\ln S=\ln Q$ \\
\hline con_s & $\begin{array}{l}-3.88^{* * *} \\
(-4.49)\end{array}$ & $\begin{array}{c}1.69 \\
(1.27)\end{array}$ \\
\hline $\ln p$ & $\begin{array}{c}0.96^{*} \\
(1.94)\end{array}$ & $\begin{array}{l}0.75^{* *} \\
(2.11)\end{array}$ \\
\hline $\ln y$ & $\begin{array}{l}1.14^{* *} \\
(2.95)\end{array}$ & - \\
\hline$i$ & $\begin{array}{c}-0.08^{* * *} \\
(-2.66)\end{array}$ & $\begin{array}{c}-0.07^{* * *} \\
(-2.98)\end{array}$ \\
\hline $\ln c$ & - & $\begin{array}{l}0.59^{* * * *} \\
(5.00)\end{array}$ \\
\hline Adj R-squared & 0.9622 & 0.9778 \\
\hline $\mathrm{F}$ & $154.55^{* * *}$ & $236.90^{* * * *}$ \\
\hline
\end{tabular}
channels in China. A direct result of the tax reform since 1994 in China was that primary distribution ratio of

Table 2. Estimated results in step (i).

Note: the " $\mathrm{t}$ " values are shown in brackets and ${ }^{*},{ }^{*},{ }^{* * *}$ is the significance level of $10 \%, 5 \%, 1 \%$, respectively. 
Z

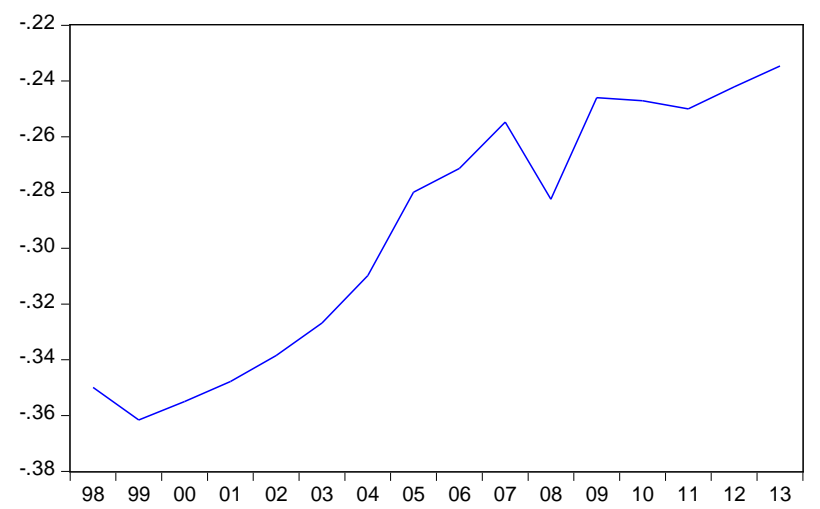

Figure 1. The time sequence diagram of the unbalanced degree $Z$.

E

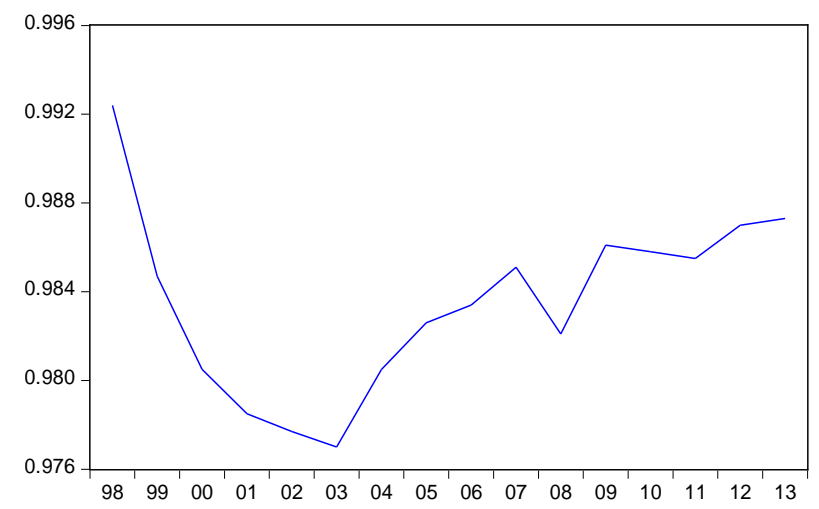

Figure 2. The time sequence diagram of market efficiency $E$.

Table 3. The estimates from 1998 to 2013.

\begin{tabular}{ccccccc}
\hline Year & $\widehat{\ln D}$ & $\widehat{\ln S}$ & $\ln Q$ & $\widehat{Z}=(\widehat{\ln D}-\widehat{\ln S}) / \ln Q$ & $\widehat{r^{2}}$ & $\hat{E}$ \\
\hline 1998 & 9.1202 & 12.4122 & 9.4080 & -0.3499 & 0.0076 & 0.9924 \\
1999 & 8.9872 & 12.4538 & 9.5858 & -0.3616 & 0.0153 & 0.9847 \\
2000 & 9.0107 & 12.5021 & 9.8329 & -0.3550 & 0.0195 & 0.9805 \\
2001 & 9.0491 & 12.5337 & 10.0173 & -0.3478 & 0.0215 & 0.9785 \\
2002 & 9.1202 & 12.572 & 10.1965 & -0.3385 & 0.0223 & 0.9777 \\
2003 & 9.2072 & 12.6146 & 10.4258 & -0.3268 & 0.0230 & 0.9770 \\
2004 & 9.4792 & 12.7481 & 10.5514 & -0.3098 & 0.0195 & 0.9805 \\
2005 & 9.7868 & 12.8449 & 10.9239 & -0.2799 & 0.0174 & 0.9826 \\
2006 & 9.8953 & 12.8902 & 11.0326 & -0.2714 & 0.0166 & 0.9834 \\
2007 & 10.1362 & 13.0041 & 11.2562 & -0.2547 & 0.0149 & 0.9851 \\
2008 & 9.9094 & 13.0437 & 11.0970 & -0.2824 & 0.0179 & 0.9821 \\
2009 & 10.3574 & 13.177 & 11.4590 & -0.2460 & 0.0139 & 0.9861 \\
2010 & 10.4154 & 13.2721 & 11.5595 & -0.2471 & 0.0142 & 0.9858 \\
2011 & 10.4451 & 13.3468 & 11.6025 & -0.2500 & 0.0145 & 0.9855 \\
2012 & 10.5856 & 13.399 & 11.6200 & -0.2421 & 0.0130 & 0.9870 \\
2013 & 10.6857 & 13.4503 & 11.7795 & -0.2346 & 0.0127 & 0.9873 \\
\hline
\end{tabular}

Note: $\quad \widehat{r^{2}}=|(\widehat{\ln D}-\ln Q) / \widehat{\ln D}| \times|(\widehat{\ln S}-\ln Q) / \widehat{\ln S}|, \quad \hat{Z}=(\widehat{\ln D}-\widehat{\ln S}) / \ln Q, \quad \hat{E}=1-\widehat{r^{2}}$ 
local fiscal revenue decreased sharply, which led to local government take the land as its main off-budget sources which would push up the housing prices and increase the housing supply [14]. At the same time, because Chinese capital market was not very perfect and investment channels were too narrow, people's high return expectation on the real estate market resulted in that a large number of saving flew into the real estate industry, which increased the housing supply.

(2) The overall absolute value of $Z$ was declining besides obvious change in 2008. We argued that obvious variation of $Z$ in 2008 was mainly caused by the impact of the global financial crisis. The result showed that commercial housing market in China gradually became more efficient after its 16-year's market-oriented operation and suggested that regulation and control policy on real estate market implemented by the Chinese government had played an important role in improving the efficiency of the real estate market operation.

As can be seen from the Figure 2:

(1) During 1998-2013, the housing market efficiency $E$ in China was high on the whole which was above 0.97 .

(2) From 1998 to 2003, " $E$ ” had been in decline and the possible reason was at the beginning of the market-oriented operation, the institution related with the real estate was imperfect and economic actors had not adapt to the market, so that all kinds of market trading friction led to a decline in market efficiency.

(3) From 2004 to 2007, housing market efficiency $E$ had been in a rising trend and reason may be that after years of market-oriented operation in commercial housing market, the economic actors gradually explored the law of the real estate market operation, at the same time, various system were constantly improved, which led to reducing trade friction and improving the market efficiency.

(4) From 2009 to 2013, E leveled off which attributed to Chinese government's effective regulation and control policy against real estate as well as all kinds of further perfect system reform.

\section{Conclusion and Advice}

In this paper, based on a perspective of disequilibrium, we measured the market efficiency of housing market in China by constructing an econometric model. The results showed that Chinese housing market was in disequilibrium and the effective housing demand was insufficient. According to the market efficiency defined by (Benassy, 1987) and "short edge rule", the market efficiency of housing market in China was high and on the rise from 1998 to 2013, which showed that the housing market in China had made great progress after its 16 years of market-oriented operation under the Chinese government's regulation and control policy against real estate. But it is far from enough. The Chinese government should take further measures to increase the effective demand of house to further improve the efficiency of markets, which will develop disequilibrium of housing market to the Walrasian equilibrium. The causes of negative disequilibrium in real estate market in China mainly include following factors such as unsound market system, imperfect market mechanism, overheating housing investment, incomplete market information, the people's uncertain prospect and so on [15]. These factors always enable the effective housing demand lower than the effective housing supply.

Based on the research conclusions of this paper, we suggested the Chinese government to further strengthen the regulation and control against real estate market in order to maintain the basic balance between total housing supply and total housing demand. Firstly, the government should strengthen the management of the amount of housing supply. Secondly, the government should curb the rising of excessive housing investment and speculative demand. For this purpose, the government may develop the affordable housing system and strictly separate the affordable housing and commercial housing market, which will effectively distinguish between the housing consumption demand and speculative demand. Thirdly, the government should build a multi-level housing structure system and promote the balance of real estate market in medium cities, at the same time, vigorously develop the secondary housing market and rental market, which will effectively meet the needs of the people from different classes and their different consumption levels of housing. Finally, the reforms of current financial system in which the local government excessively depends on land income are necessary.

\section{References}

[1] Li, Y.N. (2009) Unbalanced Chinese Economy. The Encyclopedia of China Publishing House, Beijing.

[2] Benassy, J.-P. (1987) Imperfect Competition, Unemployment and Policy. European Economic Review, 31, 417-426.

[3] Kornal, J. (1986) Shortage Economics. Cambridge University Press, Cambridge. 
[4] Burkett, J.P. (1988) Slack, Shortage, and Discouraged Consumers in Eastern Europe: Estimates Based on Smoothing by Aggregation. The Review of Economics Studies, 55, 493-505.

[5] Wang, J.M. and Gao, T.M. (2004) The Dynamic Analysis of Chinese Real Estate Market Supply and Demand Function. China Soft Science, No. 4, 69-74.

[6] Zheng, S.Q. (2007) Information Searching, Brokerage Services and Market Efficiency: Microeconomic Evidence from the Housing Market. Journal of Economic System Reform, No. 5, 161-163.

[7] Gao, T.M. (2001) Information and The Real Estate Market Efficiency. Journal of Monetary Economics, No. 8, 37-39.

[8] Hu, J.C. (2006) The Real Estate Market Efficiency Theory. Journal of Shanghai Economic Studies, No. 12, $124-126$.

[9] Ji, L.C. (2005) The Disequilibrium of the Real Estate Market. Economic Management Publishing House, Beijing.

[10] Cui, B. (2002) A Theory of Real Estate Market Efficiency. China’s Real Estate, No. 2, 99-101.

[11] Xie, B. and Shi. J.G. (2013) Measuring the Degree of Disequilibrium in Real Estate Market in Shanghai. Journal of Shanghai Economic Studies, 138-139.

[12] Guo, X.L. (2003) The Housing Market Efficiency in China: Measurement, Evaluation and Countermeasures. Journal of Economics and Management, No. 2, 40-41.

[13] Chow, G.C. and Niu, L.L. (2010) Housing Demand and Supply of Urban Residents in China. Journal of Financial Research, No. 1, 36-38.

[14] Li, H., Hong, G.Z. and Huang, L.X. (2013) A Mystery of China’s Land Finance Growth—The Tax Reform, Strategic of Land Financial Growth. Journal of Economics (Quarterly), No. 7, 1142-1143.

[15] Zhao, L. and Zhang, H.W. (2014) Based on the Theory of Unbalanced Supply and Demand Analysis of the Real Estate Market in China. Journal of Hunan University, No. 5, 71-73. 